\title{
Purification and characterization of an insulin-related peptide in the desert locust, Schistocerca gregaria: immunolocalization, cDNA cloning, transcript profiling and interaction with neuroparsin
}

\author{
Liesbeth Badisco*, Ilse Claeys*, Matthias Van Hiel, Elke Clynen, Jurgen Huybrechts, \\ Tim Vandersmissen, Sofie Van Soest, Luc Vanden Bosch, Gert Simonet and \\ Jozef Vanden Broeck
}

Department of Animal Physiology and Neurobiology, Zoological Institute K U Leuven, Naamsestraat 59, PO Box 02465, B-3000 Leuven, Belgium

(Correspondence should be addressed to J Vanden Broeck; Email: jozef.vandenbroeck @ bio.kuleuven.be)

*(L Badisco and I Claeys contributed equally to this work)

\begin{abstract}
Members of the insulin superfamily are not restricted to vertebrates, but have also been identified in invertebrate species. In the current report, we present the characterization of $S c g$-insulin-related peptide (IRP), an insulin-related peptide in the desert locust, Schistocerca gregaria. This peptide was isolated from corpora cardiaca (CC) extracts by means of a high-performance liquid chromatography (HPLC)-based purification strategy. Subsequent cloning and sequencing of the corresponding cDNA revealed that the encoded Scg-IRP precursor displays the structural organization that is typical for members of the insulin superfamily. Moreover, immunocytochemistry on brain tissue sections demonstrated the presence of Scg-IRP in median neurosecretory cells of the pars intercerebralis and their projections towards the storage part of the CC. Quantitative real-time RT-PCR studies revealed the presence of Scg-IRP transcripts in a variety of tissues, including nervous tissue and fat body. Furthermore, these transcripts showed a tissue- and phase-dependent, temporal regulation during the reproductive cycle of adult males and females. Finally, we demonstrated that Scg-IRP interacts in vitro with a recombinant neuroparsin, a locust protein displaying sequence similarity with vertebrate IGF binding proteins.
\end{abstract}

Journal of Molecular Endocrinology (2008) 40, 137-150

\section{Introduction}

Members of the insulin superfamily are not restricted to vertebrates but have also been identified in a large variety of invertebrate species where they are usually designated as 'insulin-like peptides' (ILPs) or 'insulinrelated peptides' (IRPs). An invertebrate substance with insulin-like activities was first demonstrated in the mollusk, Mya arenaria (Collip 1923), and subsequently various studies suggested the existence of insulin-like substances in a wide variety of invertebrate species. A small Bombyx mori hormone displaying prothoracicotropic activity in the related lepidopteran species, Samia cynthia, showed similarity to vertebrate insulin. The determination of its amino acid sequence represented the first structural identification of an insect IRP that was termed 'bombyxin' (Nagasawa et al. 1986). The second insect IRP to be identified was Lom-IRP, which had been isolated as a $5 \mathrm{kDa}$ peptide from corpora cardiaca extracts of the migratory locust, L. migratoria (Hetru et al. 1991). Subsequently, IRP/ILPs have also been identified in various other insects (Wu \& Brown 2006). Genome sequence information was the basis for the identification of seven distinct ILP genes in the fruit fly, Drosophila melanogaster (dilp $1-7)$, as well as in the malaria mosquito, Anopheles gambiae (AgamILP 1-7; Vanden Broeck 2001, Krieger et al. 2004). Similarly, eight ILP genes were discovered in the yellow fever mosquito, Aedes aegypti (AaegILP 1-8; Riehle et al. 2006), and two Apis mellifera ILPs (AmILP 1-2) were predicted from honey bee genome data (Wheeler et al. 2006). Furthermore, multiple studies in different metazoans have shown that the insulin/IRP signaling pathway is evolutionarily conserved and plays a crucial role in a range of fundamental and interrelated physiological processes, such as metabolism, growth, reproduction and ageing (as reviewed by Claeys et al. 2002). Interestingly, these processes also appear to be affected during phase transition in the desert locust, the species studied in the present report.

Locusts exhibit an extreme form of phenotypic plasticity: they can develop into two distinct 'phases', the solitarious and gregarious phase (Pener \& Yerushalmi 1998). Solitarious locusts tend to avoid each other whereas gregarious animals are likely to aggregate. Combined with a high reproductive capacity, this 
aggregation behavior can lead to the formation of huge locust swarms consisting of billions of individuals. Solitarious and gregarious locusts not only differ in behavior, but also display remarkable morphological and physiological differences (Uvarov 1966, Pener \& Yerushalmi 1998). In adults, the phase shift leads to important changes in reproductive physiology. The complete switch from one phase to the other (i.e. phase transition) usually requires several generations and is reversible. In addition to the insect developmental hormones, juvenile hormone and 20-hydroxyecdysone, brain-derived peptides, such as corazonin, adipokinetic hormone and several 'parsins', were already suggested to be linked to this process (Ayali et al. 1996a,b, Tawfik et al. 1999). Moreover, a phase-dependent regulation of locust neuroparsin (NPs) transcript levels was reported recently (Claeys et al. 2005). The 'parsins' were initially discovered as small neurosecretory proteins that are present in the pars intercerebralis-CC complex of the locust brain (Girardie et al. 1989, 1998, Lagueux et al. 1990, Hetru et al. 1991). Although NPs were first identified in locusts, genome and expressed sequence tags data have revealed the presence of various members of the NPs family in other arthropod species (Claeys et al. 2003). Furthermore, these small Cys-rich proteins display sequence similarity with the conserved N-terminal region of insulin-like growth factor binding proteins (IGFBPs), which possesses the hormone binding capacity (Claeys $e t a l$. 2003, Badisco et al. 2007). An IGFBP-like peptide was also identified in another invertebrate, namely the mollusk, Haliotis laevigata (Weiss et al. 2001). This molluskan IGFBP-like peptide, termed 'perlustrin', was indeed shown to interact in vitro with vertebrate ILPs, such as IGF and insulin. In adult female mosquito ovaries, a NPs-like factor, the 'ovary ecdysteroidogenic hormone' (OEH), displays ecdysteroidogenic activity (Brown et al. 1998) in a similar way to (vertebrate) insulin (Riehle \& Brown 1999). Altogether, these previous studies suggest the possible existence of a functional relationship between both IRP and NPs-like proteins in insects. Therefore, based on our interest in studying the role of parsins in desert locust reproduction and phase transition, we were eager to identify the IRP of Schistocerca gregaria, to clone the corresponding cDNA and to analyze possible tissue-, gender- and phase-dependent differences in its transcript levels. In addition, we tried to provide experimental evidence for the hypothesis that locust NPs are capable of interacting with this endogenous locust IRP.

\section{Materials and methods}

\section{Rearing of the animals}

Gregarious desert locusts, S. gregaria (Forskål), were reared under crowded conditions according to the method previously described by Vanden Broeck et al. (1998). Breeding of solitarious desert locusts was performed under isolated conditions as described by Hoste et al. (2002). Temperature, photoperiod and food supply were similar for both phases.

\section{Purification of Scg-IRP}

\section{Preparation of CC extract}

A total of 1800 locust CC were micro-dissected, rinsed in a Ringer solution (1L: $8.766 \mathrm{~g} \mathrm{NaCl} ; 0.188 \mathrm{~g}$ $\mathrm{CaCl}_{2} ; 0.746 \mathrm{~g} \mathrm{KCl} ; 0.407 \mathrm{~g} \mathrm{MgCl}_{2} ; 0.336 \mathrm{~g} \mathrm{NaHCO}_{3}$; $30.807 \mathrm{~g}$ sucrose; $1.892 \mathrm{~g}$ trehalose; $\mathrm{pH} 7.2$ ) and collected in chilled acidified ethanol $(75 \% \mathrm{EtOH}$, $0 \cdot 2 \mathrm{M} \mathrm{HCl}$ ). This solution was ultrasonically homogenized (Sanyo MSE Soniprep 150) and subsequently centrifuged at $10000 \mathrm{~g}$ for $30 \mathrm{~min}$ (Sorvall, Beckmann, Germany). The remaining pellet was extracted once again with acidified ethanol. Both supernatants were pooled and the organic solvent was evaporated (Büchi Rotavapor, Büchi Laboratory Equipment, Flawil, Switzerland). The remaining aqueous solution was delipidated by ethylacetate and $n$-hexane extractions. Remnants of organic solvents were removed in the rotavapor and the resulting extract was used for HPLC analysis.

\section{High performance liquid chromatography}

The first separation step was performed on a Waters Delta 600 HPLC. The chromatography was carried out on a preparative Deltapack $\mathrm{C}_{4}$ column $(25 \mathrm{~mm} \times$ $100 \mathrm{~mm}$; particle size $15 \mu \mathrm{m}, 100 \AA$ ) at ambient temperature and flow rate of $12 \mathrm{ml} / \mathrm{min}$. The prepared sample was then transferred to the injector and immediately after injection a linear gradient, from $0 \%$ to $90 \% \mathrm{CH}_{3} \mathrm{CN}$ containing $0 \cdot 1 \%$ trifluoroacetic (TFA), was initiated. The eluting peptides were detected with a variable wavelength u.v. detector, set at $214 \mathrm{~nm}$ (Waters 2487). Fractions of $12 \mathrm{ml}$ were collected every minute, from 0 to $90 \mathrm{~min}$. Aliquots (1/60 volume) of these fractions were tested in a dot blot assay, using an antibody against Lom-IRP (Riehle et al. 2006). The most intensely stained fraction was evaporated to remove $\mathrm{CH}_{3} \mathrm{CN}$ and subsequently run on a Gilson HPLC system. The separation of the compounds in this second run was carried out on a Waters semi-preparative Spherisorb $\mathrm{C}_{1}$ column $(10 \mathrm{~mm} \times 250 \mathrm{~mm}$, particle size $10 \mu \mathrm{m})$ at ambient temperature and at a flow rate of $2 \mathrm{ml} / \mathrm{min}$. Immediately after injection, a linear gradient was started from $2 \%$ to $50 \% \mathrm{CH}_{3} \mathrm{CN}$ containing $0 \cdot 1 \%$ TFA. The eluting peptides were detected with a variable wavelength u.v. detector, which was set at $214 \mathrm{~nm}$ (Waters 486 Tunable Absorbance Detector). Fractions 
of $2 \mathrm{ml}$ were collected every minute, from 0 to $60 \mathrm{~min}$. Small aliquots $(1 / 60$ volume) were again sacrificed in a dot blot assay.

\section{Dot blot assay}

Aliquots of HPLC fractions were evaporated in a vacuum centrifuge and subsequently dissolved in $5 \mu \mathrm{l}$ $10 \% \mathrm{CH}_{3} \mathrm{CN} / 0 \cdot 1 \%$ TFA. Two microliters of each sample was spotted onto a nitrocellulose membrane (Hybond-C, Amersham), which was then baked for $30 \mathrm{~min}$ at $120^{\circ} \mathrm{C}$. Membranes were blocked with $3 \%$ skimmed milk in $50 \mathrm{mM}$ Tris-buffered saline and incubated overnight at $4{ }^{\circ} \mathrm{C}$ with 1:500 diluted primary antiserum. The primary antibody, prepared in rabbit and directed against the A-chain of Lom-IRP, was a kind gift of Prof. M Brown (Department of Entomology, University of Georgia, Athens, GA, USA; Riehle et al. 2006). After rinsing, blots were incubated with a goat anti-rabbit horseradish peroxidase conjugated antibody (Dako, Carpinteria, CA, USA) for $45 \mathrm{~min}$, rinsed and developed with 3,3'-diaminobenzidine (DAB) as substrate (Sigma-Aldrich).

\section{Mass analysis and amino acid sequencing}

Immunopositive fractions were subsequently analyzed by mass spectrometry (MALDI-TOF; Reflex IV, Brüker daltonics $\mathrm{GmbH}$, Bremen, Germany). Aliquots of samples were loaded on a multi-sample target using $\alpha$-cyano-4-hydroxycinnamic acid as matrix and measured in linear mode. A fraction containing a potential IRP was further sequenced by Edman degradation. Therefore, the fraction was dried in a vacuum centrifuge and reconstituted in $10 \mu \mathrm{l}$ acetonitrile/water/TFA (50:49.9:0.1 v/v/v) solution. $\mathrm{N}$-terminal amino acid sequencing was carried out on a Procise 491 micro-sequencer (Applied Biosystems). The amino acids were detected by a 785-A Programmable Absorbance Detector (Applied Biosystems). Reagents required for the Edman degradation and solvents required for gradient elution were obtained from Applied Biosystems. Amino acids were identified by comparison with a standard mixture (Procise Software, Applied Biosystems, Foster City, CA, USA).

\section{Immunocytochemistry}

Locust brains were micro-dissected, rinsed in Ringer solution, and then transferred to Bouin Hollande's $(10 \%)$ sublimate fixative (18-24 h). Fixed tissues were rinsed with distilled water for $12 \mathrm{~h}$, dehydrated in an ethanol series, cleared overnight in histosol/paraplast $(50: 50 \mathrm{v} / \mathrm{v})$ and embedded in paraplast. Alternating sections of $4 \mu \mathrm{m}$ were made with a LKB Historange glass microtome (LKB, Stockholm, Sweden). Sections were rehydrated and processed according to the peroxidase anti-peroxidase immunocytochemistry method (Vandesande \& Dierickx 1976) using DAB as chromogenic substrate. The primary rabbit antibody, raised against the A-chain of Lom-IRP (Riehle et al. 2006), was applied in a dilution of $1 / 500$.

\section{Preparation of RNA and cDNA}

Desert locust tissues were micro-dissected under a binocular microscope and immediately collected in RNAlater solution (Ambion) to prevent degradation. Until further processing, pooled tissue samples (each sample was derived from ten individuals) were stored at $-20{ }^{\circ} \mathrm{C}$. Samples were added to reaction tubes containing Green Beads and homogenized in the MagNA Lyser instrument (Roche). Subsequently, total RNA was extracted from the resulting homogenates utilizing the RNeasy Lipid Tissue Mini Kit (Qiagen). In combination with this extraction procedure, a DNase treatment (RNase-free DNase set, Qiagen) was performed to eliminate potential genomic DNA contamination. After spectrophotometric quantification and quality control with the Agilent 2100 Bioanalyser (Agilent Technologies), $1 \mu \mathrm{g}$ of the resulting total RNA was reverse transcribed (Superscript II, Invitrogen) utilizing random hexamers according to the company's protocol. Afterwards, the resulting cDNA was diluted tenfold.

\section{Cloning of the Scg-IRP cDNA}

\section{Partial cDNA cloning by PCR}

The PCR primer sets (I and II) were initially based on the amino acid sequence of the A- and B-chains of $S c g$-IRP (cf. Edman degradation) and on the nucleotide sequence of Lom-IRP. These primers had the following sequences:

$\rightarrow 5^{\prime}$-CGGCGAGAAGCTCTCCAA-3' ${ }^{\prime}$ (I)

$\leftarrow 5^{\prime}$-CCTTCTTGAACATGGTGTTGTAGTTG-3' (I)

$\rightarrow 5^{\prime}$-GACGAGTGCTGCCGCAAGA-3' (II)

$\leftarrow 5^{\prime}$-TAGCGGCGGCCGCAGTAG-3' (II).

Since sequence information of the resulting PCR fragments revealed that the coding sequences of $S c g$-IRP and Lom-IRP were nearly identical, a new set of primers spanning the open reading frame (ORF) was designed based on the Lom-IRP coding sequence:

$\rightarrow 5^{\prime}$-ATGTGGAAGCTGTGCCTCCGACTGCTCG-3'

$\leftarrow$ 5'-GGCCGCAGTAGGTCTGCAGCTCGCTGAT-3'

The PCR was performed with Pwo SuperYield DNA Polymerase (Roche), because the amplification efficiency appeared to be low when Taq polymerase was 
used, probably due to the presence of GC-rich regions in the $S c g$-IRP cDNA. The total reaction volume was $50 \mu \mathrm{l}$, including $5 \mu \mathrm{l}$ cDNA template, $5 \mu \mathrm{l} 10 \times$ PCR buffer (Roche), $1 \mu \mathrm{l}$ dNTP mix (2.5 mM for each dNTP), $10 \mu \mathrm{l}$ GC-rich resolution solution (Roche), $5 \mu \mathrm{l}$ each primer $(10 \mu \mathrm{M})$ and $0.5 \mu \mathrm{l}$ Pwo SuperYield DNA polymerase ( $5 \mathrm{U} / \mu \mathrm{l}$, Roche). Hot-start PCR was performed in a Thermocycler (Biometra, Göttingen, Germany). After an initial incubation at $95^{\circ} \mathrm{C}$ for $2 \mathrm{~min}$, thermal cycling (45 cycles) consisted of a denaturation step at $95^{\circ} \mathrm{C}$, an annealing step at $70^{\circ} \mathrm{C}$ and an extension step at $68^{\circ} \mathrm{C}$, for $1 \mathrm{~min}$ each. A final extension step was applied at $72{ }^{\circ} \mathrm{C}$ for $7 \mathrm{~min}$.

\section{Rapid amplification of cDNA Ends (RAcE)}

Based on the sequence of the ORF fragment, the following primers were designed for RAcE.

Primer for 5'-RAcE: 5'-GTTGGAGAGCTTCTCGCCGCA-3'

Primer for 3'-RAcE: 5'-GGCTTCCCAAGATGTGTCGGACGCGG-3'.

The RAcE reactions were performed with the $\mathrm{BD}$ SMART RAcE cDNA amplification kit (BD Biosciences, Clontech, San Jose, CA, USA) according to the manufacturer's protocol. However, due to amplification difficulties, Pwo SuperYield DNA polymerase had to be employed for the 3'-RAcE reaction, instead of Taq polymerase. The following temperature profile was applied: 5 cycles with a denaturation step at $94^{\circ} \mathrm{C}$ for $30 \mathrm{~s}$ and annealing/extension at $72{ }^{\circ} \mathrm{C}$ for 3 min, 5 cycles with denaturation at $94^{\circ} \mathrm{C}$ for $30 \mathrm{~s}$, annealing at $70{ }^{\circ} \mathrm{C}$ for $30 \mathrm{~s}$ and extension at $72^{\circ} \mathrm{C}$ for $3 \mathrm{~min}$, and 40 cycles with denaturation at $94^{\circ} \mathrm{C}$ for $30 \mathrm{~s}$, annealing at $68^{\circ} \mathrm{C}$ for $30 \mathrm{~s}$ and extension at $72^{\circ} \mathrm{C}$ for $3 \mathrm{~min}$.

\section{Analysis of PCR and RAcE fragments}

Amplification products were analyzed by horizontal agarose gel electrophoresis and purified using the GenElute gel extraction kit (Sigma-Aldrich). The DNA fragments were subcloned into the pCRII vector via the TOPO TA Cloning Kit (Invitrogen). The DNA sequences were determined using the ABI PRISM 3130 Genetic Analyzer (Applied Biosystems) following the protocols outlined in the ABI PRISM BigDye Terminator Ready Reaction Cycle Sequencing Kit (Applied Biosystems).

\section{Quantitative real-time RT-PCR}

The RT-PCRs were performed in $25 \mu \mathrm{l}$ volume, containing $5 \mu$ diluted cDNA sample, according to the Power SYBR Green PCR Master Mix protocol (Applied Biosystems). The final concentration of the primers was $300 \mathrm{nM}$. In order to compensate for possible variations due to pipetting errors and differences in reverse transcriptase efficiency, a $S$. gregaria $\beta$-actin transcript was analyzed as an endogenous control. Our previous studies indicated that the levels of this mRNA remain quite constant in locust tissues, regardless of developmental or physiological conditions (Vanden Broeck et al. 1998, Janssen et al. 2001, Claeys et al. 2003). Primers for the endogenous control were described previously (Claeys et al. 2005). Those for the Scg-IRP, target sequence were designed by means of the Primer Express software package (Applied Biosystems):

\section{$S c g$-IRP: $\rightarrow$ 5'-CCGTGGCAACTACAACACCAT-3' $\leftarrow 5^{\prime}$-TCCGCGTCCGACACATCT-3'}

The reactions were run in duplicate on an ABI PRISM 7000 Sequence Detection System (Applied Biosystems) applying the following thermal cycling profile: $2 \mathrm{~min}$ at $50^{\circ} \mathrm{C}, 10 \mathrm{~min}$ at $95^{\circ} \mathrm{C}$, followed by 40 cycles of $15 \mathrm{~s}$ at $95^{\circ} \mathrm{C}$ and $60 \mathrm{~s}$ at $60^{\circ} \mathrm{C}$. Data were analyzed according to the comparative $C_{\mathrm{T}}$ method by means of the ABI PRISM 7000 SDS software (Applied Biosystems, version 1.2.3). The specificity of the PCRs was double-checked. Analysis of the dissociation curves of $S c g$-IRP and $\beta$-actin amplification products revealed a single melting peak. In addition, PCR products were analyzed via agarose gel electrophoresis, showing the presence of a single band of the expected size for each transcript. Furthermore, sequencing of the PCR products ultimately confirmed the identity of the amplified DNA. For each sample, the relative amount of transcript was normalized to the endogenous control and transcript levels were calculated relative to a calibrator sample (day 4 female brains). All experiments were repeated three times with independent samples. Statistical analysis was performed by means of Statistica 7.1 (StatSoft, Tulsa, OK, USA) and consisted of the Mann-Whitney $U$ test for comparing two independent groups. A level of $P<0.05$ was considered significant.

\section{Binding Of Scg-NP4}

\section{Vector for Scg-NP4 expression}

The Drosophila inducible/secreted expression system (Invitrogen) results in the biosynthesis of a recombinant gene product in Drosophila Schneider $2\left(\mathrm{~S}_{2}\right)$ cells. The vector $\mathrm{pMT} / \mathrm{BiP} / \mathrm{V} 5$-His codes for an N-terminal, secretory signal peptide, which directs the product towards the culture medium, as well as a C-terminal peptide containing a V5-epitope for antibody detection and a polyhistidine $(6 \times$ His $)$ tag for binding onto a nickel column and subsequent affinity purification of the protein of interest. Furthermore, the expression of recombinant product is controlled by a metallothionein gene promoter (pMT). Transcription of metallothionein genes is regulated in a heavy metal-dependent manner. 
Hence, expression of pMT-controlled genes can be induced by adding copper ions (or other heavy metal ions) to the cell culture medium.

Based on the nucleotide sequence of the $S c g$-NP4 precursor (Claeys et al. 2003), a set of primers was designed for selective amplification of the cDNA fragment that codes for $S c g$-NP4. The upstream primer contained a BglII restriction site whereas the downstream primer included a recognition site for XhoI. Since both sites are also present in the multiple cloning site of the $\mathrm{pMT} / \mathrm{BiP} / \mathrm{V} 5$-His vector, this allowed for directional insertion of the fragment. Digestion of $\mathrm{pMT} / \mathrm{BiP} / \mathrm{V} 5$ His and the amplified fragment was performed with BglII and XhoI (Roche). After ligation (Rapid DNA Ligation
Kit, Roche) and transformation in Escherichia coli DH5 $\alpha$ cells (Invitrogen), the expression construct was verified by DNA sequencing. Subsequently, recombinant colonies were subjected to an endotoxin-free Maxiprep (Qiagen) procedure.

\section{Biosynthesis and purification of Scg-NP4}

The Drosophila $\mathrm{S}_{2}$ cells were cultured at $23^{\circ} \mathrm{C}$ in Schneider's Drosophila medium (Serva Electrophoresis $\mathrm{GmbH}$, Heidelberg, Germany) supplemented with $5.45 \mathrm{mM} \mathrm{CaCl}, 4.44 \mathrm{mM} \mathrm{NaHCO} 3,50 \mathrm{U} / \mathrm{ml}$ penicillin, and $50 \mu \mathrm{g} / \mathrm{ml}$ streptomycin (Invitrogen) and $10 \%$ heatinactivated fetal calf serum (Invitrogen). Transfections
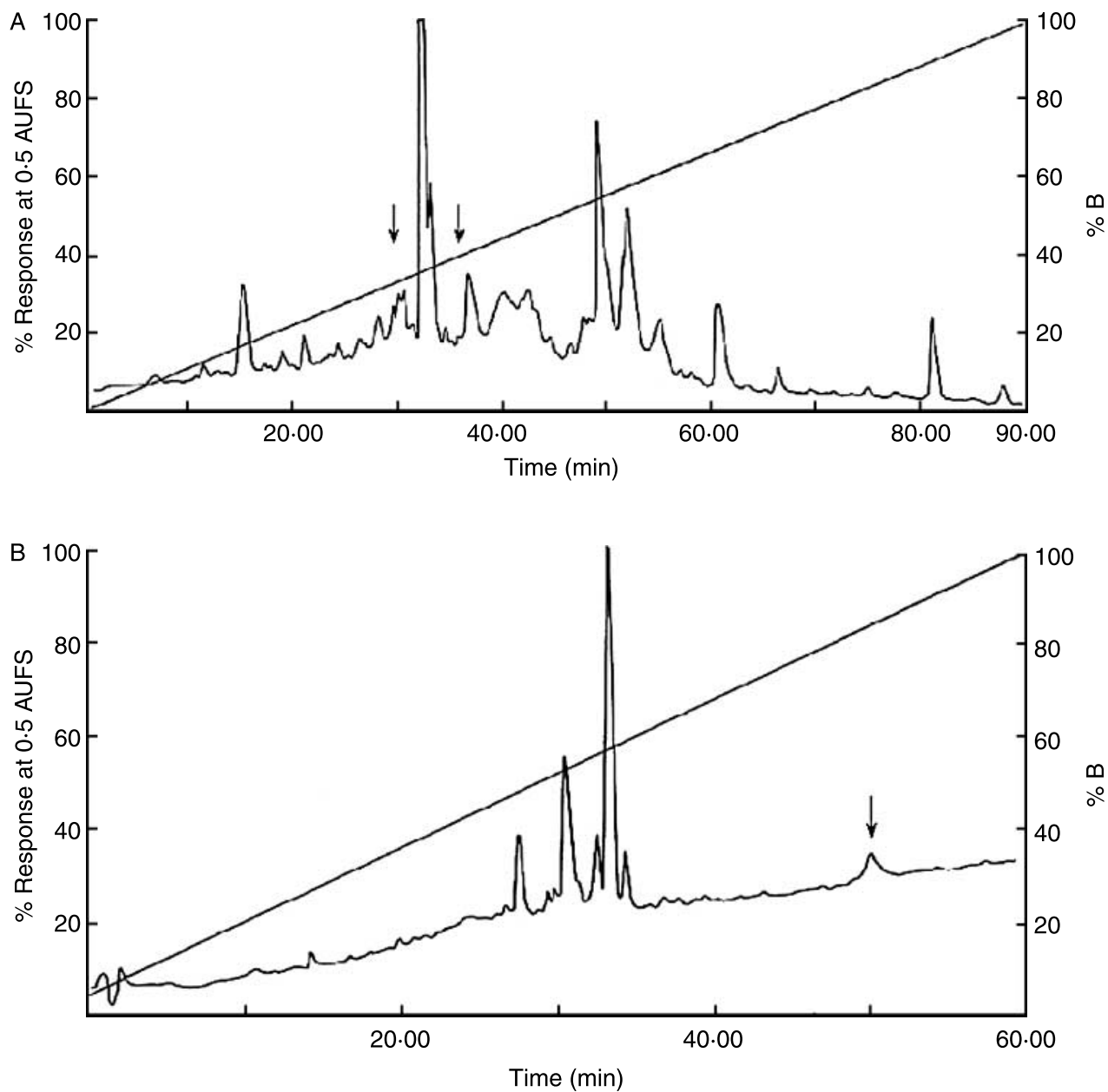

Figure 1 Chromatograms of the HPLC runs that resulted in the purification of Scg-IRP, a desert locust insulin-related peptide. (A) In the first run, an extract of 1800 corpora cardiaca was fractionated on a preparative Waters DeltaPack $\mathrm{C}_{4}$ column with a linear gradient from $100 \% \mathrm{~A}(0 \cdot 1 \%$ TFA $)$ to $100 \% \mathrm{~B}(0 \cdot 1 \%$ TFA $/ 90 \%$ acetonitrile) within $90 \mathrm{~min}$ at a flow rate of $12 \mathrm{ml} / \mathrm{min}$. (B) Fraction 31 was further fractionated in the second run on a Waters semi-preparative Spherisorb $C_{1}$ column with a linear gradient from $100 \% \mathrm{~A}$ $(0.1 \%$ TFA $)$ to $100 \%$ B $(0.1 \%$ TFA $/ 50 \%$ acetonitrile $)$ within $60 \mathrm{~min}$ at a flow rate of $2 \mathrm{ml} / \mathrm{min}$. The eluted peptides were monitored with a variable wavelength u.v. detector, set at $214 \mathrm{~nm}$. Fractions were collected every minute, their numbers corresponding to the elution time. Arrows indicate the range of fractions that were stained positive in a dot blot assay with anti-Lom-IRP antiserum. 
were carried out in serum-free Schneider's Drosophila medium with $6 \mu \mathrm{l}$ Cellfectin (Invitrogen) and $1 \mu \mathrm{g}$ DNA per $10^{6}$ cells. Co-transfection was performed with a pCoHygro selection plasmid (carrying a hygromycin B resistance gene) in order to obtain a stable cell population. For peptide production, hygromycin B selected cells were grown in Drosophila serum-free medium (Invitrogen). After the cells had reached the exponential phase of their growth curve $\left(2-4 \times 10^{6}\right.$ cells $/ \mathrm{ml}$ ), recombinant NPs expression was induced
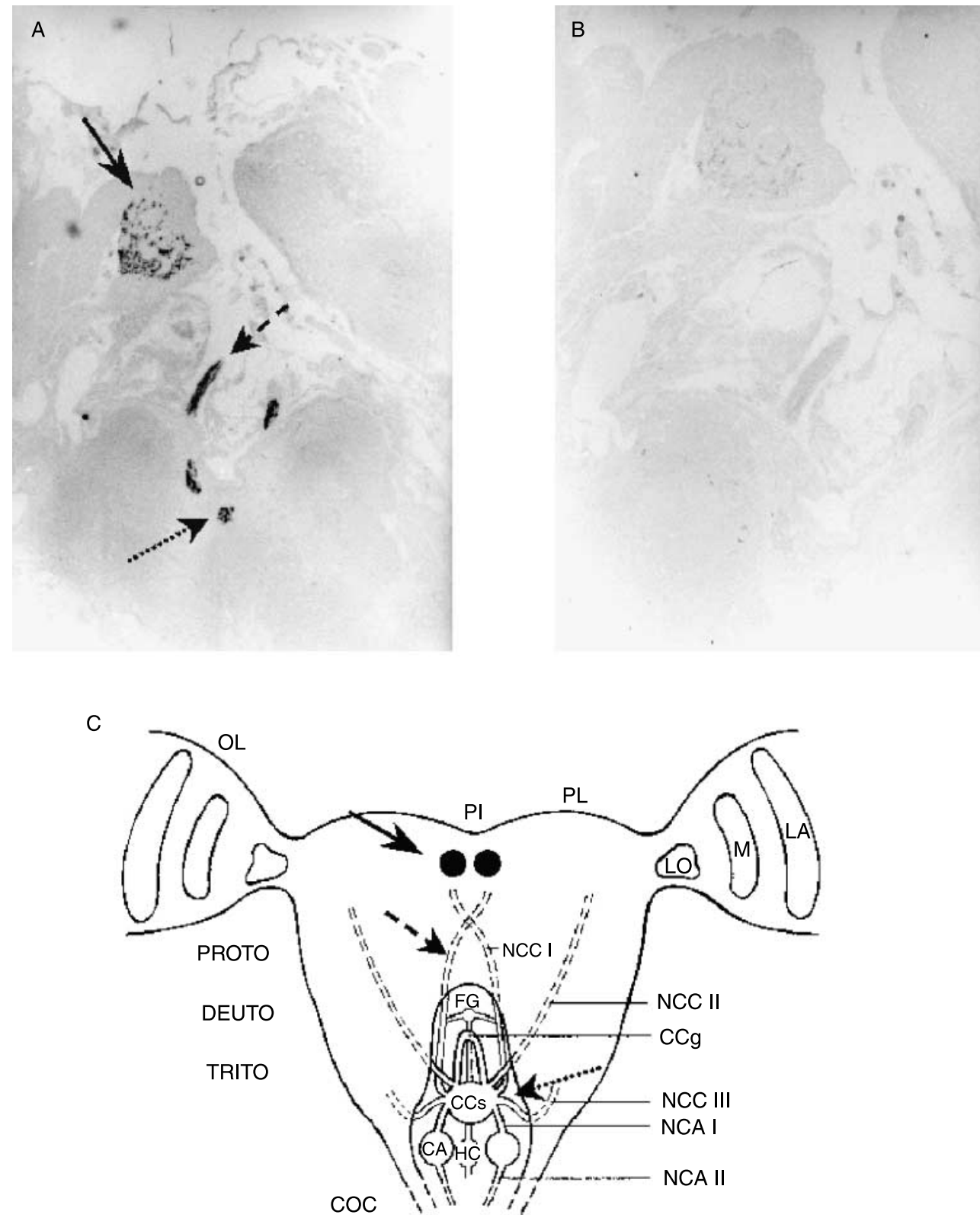

Figure 2 Immunohistochemical analysis of IRP-like immunoreactivity in desert locust (S. gregaria) brain. (A) Immunopositive staining is visualized in the pars intercerebralis (full arrow), nervus corporis cardiaci I (broken arrow) and corpus cardiacum (dotted arrow). (B) Alternating tissue section incubated with the preimmune serum as negative control. (C) Scheme of the desert locust brain showing the localization of IRPlike immunoreactivity. Immunoreactive fibers and terminals are present in the storage part of the CC (arrow); cell bodies are located in the PI (arrow). Abbreviations: CA, corpus allatum; CCg, corpus cardiacum glandular part; CCs, corpus cardiacum storage part; COC, circumesophageal connectives; DEUTO, deutocerebrum; FG, frontal ganglion; HC, hypocerebral ganglion; LA, lamina; LO, lobulla; M, medulla; MN, median nerve; NCA I, II, nervi corporis allati; NCC I, II, III, nervi corporis cardiaci; OL, optic lobe; PI, pars intercerebralis; PL, pars lateralis; PROTO, protocerebrum; TRITO, tritocerebrum. 
AGTCCGCGGGTTGGTCGGCCAGGCGGCACTCGGCACTCCTGCAAGCTGTGGCAGCTCCT AGACGCCGCT GCGCCCCT CCAGGA TTCT GCTCTCCAGTCACCGCCCACCGCT GCA GACCGAG......................

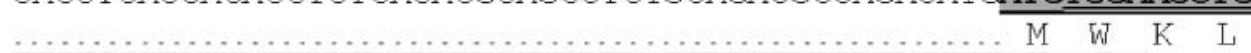
TGCCTCCGACTGCTCGCCGTGCTGGCGGTGTGCCTGT GCACGGCCACGCAGGCGCAGTC $\begin{array}{llllllllllllllllllll}C & L & R & L & L & A & V & L & A & V & C & L & C & T & A & T & Q & A & Q & S\end{array}$ CGACCTGTTCCTCCTGTCGCCCAAGCGOAGCGGCGCGCCGCAGCCGGTGGCCCGCTACT

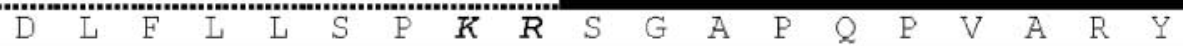
GCGGCGAGAAGCTCTCCAACGCGCTCAAGATCGPCTGCCGTGGCAACTACAACACCATG

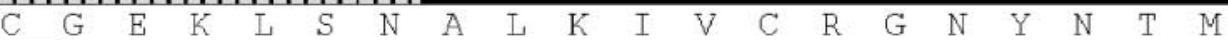
TTCAAGAAGGCTTCCCAAGATGTGTCGGACGCGGAGTCTGAAGACAACTACTGGAGCCA

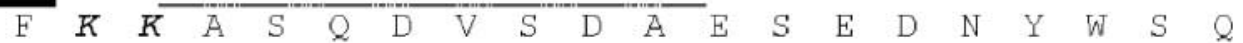
GTCGGCCGACGAGGAGGTGGAGGCGCCGGCGCT GCCGCCGTACCCCGT GCTGGCGCGGC $\begin{array}{lllllllllllllllllllllllllll}S & A & D & E & E & V & E & A & P & A & L & P & P & Y & P & V & L & A & R\end{array}$ CGAGCGCGGGTGGCCTGCTCACCGCCGCGGTCTTCCGGCGGCGCACGCGCGGCGTCTTC $\begin{array}{lllllllllllllllllllll}P & S & A & G & G & L & L & T & A & A & V & F & R & R & R & T & R & G & V & F\end{array}$ GACGAGTGCTGCCGCAAGAGCTGCAGCATCAGCGAGCTGCAGACGTACTGCGGCCGCCG $\begin{array}{llllllllllllllllllll}\mathrm{D} & \mathrm{E} & \mathrm{C} & \mathrm{C} & \mathrm{R} & \mathrm{K} & \mathrm{S} & \mathrm{C} & \mathrm{S} & \mathrm{I} & \mathrm{S} & \mathrm{E} & \mathrm{I} & \mathrm{Q} & \mathrm{T} & \mathrm{Y} & \mathrm{C} & \mathrm{G} & \boldsymbol{R} & \boldsymbol{R}\end{array}$ GTAGTCGCCGCAGCCGCTCCACCGCCGCGCCGCGCGCCACTTATTTATTGTCCCTGTCA *

GCCGGGGCGGGCCAGACCGCGAGGCCAGCCCCCGGCGGTACAGGGGCCGGCCGAAGCCG CGCTCGCCTCTCGCAAGCAACGCACGAGGGGGCGCCCGCGCTTCCGATCAGTATTATTC TTCTTATTTCGCATTTGTTTTTACTGCAAATTGTATACGTTTCATGTGATTCGTAAGAC GAAAGTTGGTACAAAAAAAGCGTTCAAAACTCGTGAAAATAAACTTACATGTGCACAAG TAAAAAAAAAAAAAAAAAAAAA

B $\begin{array}{ll}\text { S C } 9-I R P & \text { MWKLCLRLIAVLAAVCLCTATQAOSDLFLLSPKRSGAPQPVARYCGEKLS } \\ \text { LOM-IRP } & \text { MWKLCLRLIAVLAAVCLSTATOAOSDLFLLSPKRSGAPOPVARYCGEKLS }\end{array}$ Lom-IRP MWKLCLRLLAVLAVCLSTATQAOSDLFILSPRFSGAPQPVARYCGEKLS SCg-IRP NALKIVCRGNYNTMFKKASQDVSDAESEDNYWS-QSADEEVEAP--ALP LOM-IRP NALKLVCRGNYNTMFKKA.SQDVSDSESEDNYWSGQSADEAAEAAAAALP

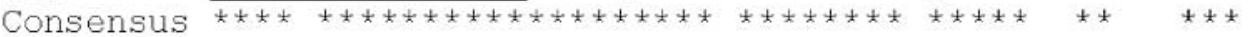
SCg-IRP PYPVLARPSAGGLLTAAVERRRTRGVFDECCRKSCS ISELQTYCGRR LOM-IRP PYPILARPSAGGLLTGAVERRRTRGVFDECCRKSCS ISELQTYCGRR

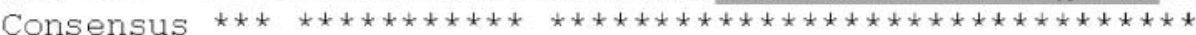

Figure 3 (A) Sequence of the Scg-IRP precursor cDNA (Scg-IRP T2) and the corresponding amino acid sequence. Consecutively, the coding sequences for the signal peptide (highlighted in gray, characters in bold black), the IRP co-peptide (characters in bold black, dotted underline), the B-chain (highlighted in black, characters in white), the C-chain (characters in bold gray) and the A-chain (highlighted in gray, characters in black) are represented. Start and stop codons, and the polyadenylation signal are underlined (single line). Predicted basic cleavage sites are denoted in bold italics. The sequence of an alternative transcript variant (Scg-IRP T1) is denoted in gray italics. The primers used for cloning the ORF are double underlined, the primer used for $5^{\prime}$ RAcE is underlined with dashes and points, and the primer used for $3^{\prime}$ $\mathrm{RAcE}$ is dashed underlined. (B) Pairwise sequence alignment of the newly identified Scg-IRP precursor with that of Lom-IRP. The alignment was performed by ClustalW analysis (http://www.ebi.ac.uk/clustalw/), available from the European Bioinformatics Institute. All parameters were set at default values.

Consecutively, the amino acid sequences of the signal peptide, the IRP copeptide, the B-chain, the C-chain and the A-chain (representation as in A) are shown. Predicted basic cleavage sites are denoted in bold italics. Conserved residues are denoted with '*' in the consensus line. 
( $48 \mathrm{~h}$ ) by adding $\mathrm{CuSO}_{4}$ to a final concentration of $500 \mu \mathrm{M}$. Recombinant $S c g$-NP4-V5-His in the culture medium $(240 \mathrm{ml})$ was then concentrated by means of Centricon 80 cartridges (cut-off membrane of $5000 \mathrm{kDa}$; Amicon) to a final volume of $6 \mathrm{ml}$. A $10 \mathrm{ml}$ column was filled with $3 \mathrm{ml}$ His-Select Nickel Affinity Gel (Sigma-Aldrich). First, the column was washed with $6 \mathrm{ml} \mathrm{H}_{2} \mathrm{O}_{\text {dest }}$ and subsequently three times with $6 \mathrm{ml}$ equilibration buffer ( $50 \mathrm{mM}$ sodium phosphate, $\mathrm{pH} 8 \cdot 0$; $0.3 \mathrm{M}$ sodium chloride; $10 \mathrm{mM}$ imidazole). Then, the column was loaded with $6 \mathrm{ml}$ concentrated $S c g$-NP4-V5His solution. The gel and medium were incubated for $1 \mathrm{~h}$ at ambient temperature, keeping the gel suspended by attaching the column to a rotating wheel. Next, the column was washed eight times with $6 \mathrm{ml}$ equilibration buffer. Finally, the recombinant protein was eluted with elution buffer ( $50 \mathrm{mM}$ sodium phosphate, $\mathrm{pH} 8 \cdot 0 ; 0 \cdot 3 \mathrm{M}$ sodium chloride; $200 \mathrm{mM}$ imidazole) and 10 fractions of $1 \mathrm{ml}$ were collected. Fractions were analyzed by means of SDS-PAGE. The eluted fractions containing the recombinant protein were desalted on PD-10 columns (Amersham-Pharmacia Biotech) and concentrated in a vacuum centrifuge to a final volume of $1 \mathrm{ml}$. The presence, purity and integrity of the protein were assessed by SDS-PAGE (Laemmli 1970) using a precast NuPAGE Novex 4-12\% Bis-Tris gel, MES buffer and the protein electrophoresis system (all Invitrogen). A protein ladder (SeeBlue Prestained standard, Invitrogen) was run in parallel with an affinity purified protein sample. Following electrophoresis, the gel was stained in Coomassie Brilliant Blue solution (overnight) and proteins were visualized after destaining in a methanol acetic acid solution. As an additional control, purified material was partially sequenced by Edman degradation.

\section{Binding assay}

The $S c g$-NP4-V5-His (200 $\mu \mathrm{l}$ concentrated sample) was loaded onto a $\mathrm{Ni}^{2+}$-column ( $1 \mathrm{ml}$ volume), which was pretreated as described above. After rinsing the column three times with $2 \mathrm{ml}$ equilibration buffer, $200 \mathrm{CC}$ equivalents of purified $S c g$-IRP, dissolved in $2 \mathrm{ml}$ equilibration buffer, were added to the nickel resin already containing $S c g$-NP4-V5-His and both were incubated overnight at ambient temperature using a rotating wheel in order to keep the resin suspended. In parallel, the same amount of $S c g$-IRP was loaded onto an empty nickel column (which did not contain Scg-NP4-V5His). Both resins were rinsed eight times with $2 \mathrm{ml}$ equilibration buffer. Next, peptides were eluted from the resin with $2 \mathrm{ml}$ elution buffer and this was repeated seven times. Wash and elution fractions were analyzed for the presence of $S c g$-NP4-V5-His and/or $S c g$-IRP by means of a dot blot assay, in which recombinant $S c g-\mathrm{NP} 4-\mathrm{V} 5-\mathrm{His}$ and $S c g$-IRP were detected by antibodies against the V5 epitope (Invitrogen) and the A-chain of Lom-IRP respectively.

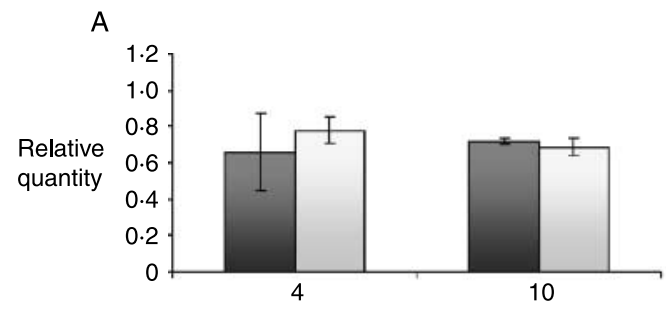

B

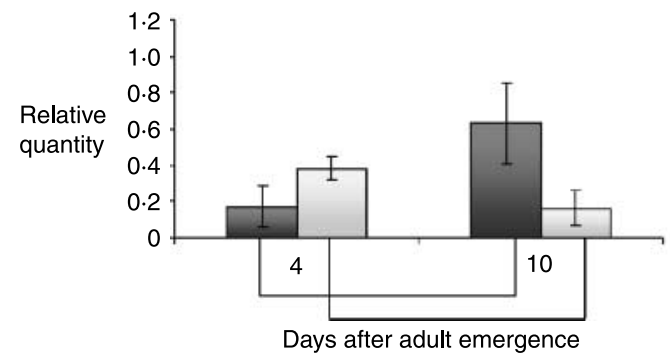

C

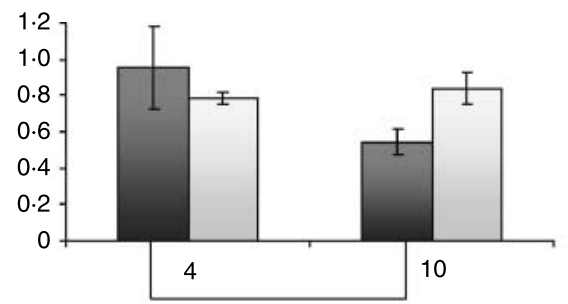

D

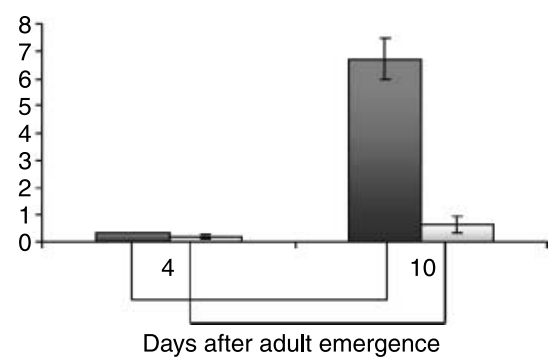

Figure 4 Relative quantity of the Scg-IRP mRNA in brain and fat body, represented per gender, in function of the number of days (4 or 10) after adult emergence. Dark gray graphs represent the results for gregarious desert locusts and light gray graphs for solitarious locusts. Results were obtained by analyzing three independent groups of ten individuals per condition and are represented as means \pm S.D. Statistical analysis was performed by means of 'Statistica 7.1' and consisted of the Mann-Whitney U test for comparing two independent groups. Significant differences $(P<0.05)$ are represented by connecting lines between the corresponding graphs. (A) Male brain, (B) male fat body, (C) female brain and (D). female fat body. 


\section{Results}

\section{HPLC purification of Scg-IRP}

Fractions of the first HPLC run, which eluted between 29 and $36 \mathrm{~min}$, resulted in positive staining (Fig. 1A) during the dot blot assay. Next, fraction 31 that was the most positively stained fraction was further analyzed by reversed-phase HPLC. From the subsequent dot blot assay, one positively immunostained fraction was obtained, which eluted at 51 minutes corresponding to $42 \cdot 5 \% \mathrm{CH}_{3} \mathrm{CN}$ (Fig. 1B). Part of this fraction $(1 / 60)$ was subsequently analyzed by MALDI-TOF MS, revealing an average mass of $5736 \mathrm{kDa}$, which was in accordance with the expected mass of a potential ILP.

Since the IRP was not reduced, each Edman degradation cycle revealed two amino acids, one of the A-chain and one at the corresponding position in the B-chain. When all cycles were run, the following amino acid sequences were revealed:

\section{A-chain: GVFDECCRKSCSISXLQTYCG \\ B-chain:}

\section{SGAPQPVARYCGEKLSNALKIVCRGNYNTMF.}

Edman degradation revealed the complete amino acid sequence of both the A-and B-chains of $S c g$-IRP, with the exception of the amino acid at position 15 of the A-chain (X). Comparison of the amino acid sequence with the only other identified IRP from Orthopteroidea, namely Lom-IRP, revealed that one amino acid was different: at position 21, the B-chain of $S c g$-IRP contains an isoleucine (I) instead of a leucine (L) in Lom-IRP. The A-chain appears to be identical in both locusts. Hence, the antibody against the complete A-chain of Lom-IRP can also be used for specific detection of $S c g$-IRP.

\section{Immunolocalization in the brain}

Alternating desert locust brain sections were incubated with rabbit polyclonal antibody raised against the A-chain of Lom-IRP and the rabbit pre-immune serum respectively. Intensely stained median neurosecretory cells were observed within the pars intercerebralis. Furthermore, immunopositive staining was also observed in the neurohemal storage part of the CC and in the connecting nerves between the pars intercerebralis and the CC, namely the nervi corporis cardiaci I (NCC-I; Fig. 2).

\section{Cloning of the Scg-IRP cDNA}

Sequencing of the obtained PCR fragments revealed the amino acid at position 15 as glutamic acid (E), identical to the A-chain of Lom-IRP (Fig. 3B). Next, primers for the RAcE reactions were derived from the partial cDNA sequence obtained by PCR. The RAcE-PCR strategy resulted in the identification of two transcript sequences that differed only in their $5^{\prime}$-untranslated region. These cDNA sequences and the deduced amino acid sequence of the encoded pre-pro-Scg-IRP precursor are represented in Fig. 3(A). When entering the $S c g$-IRP precursor amino acid sequence into the SignalP 3.0 algorithm (Center for Biological Sequence Analysis, Technical University of Denmark, Lyngby, Denmark) (Bendtsen et al. 2004), the most probable cleavage site for the signal peptide is between position 22 and 23, as was also observed for Lom-IRP (Clynen et al. 2003).

\section{Distribution of the Scg-IRP transcripts}

In both solitarious and gregarious locusts, the presence of $S c g$-IRP mRNA was detectable in virtually all tissues that were tested, i.e. nervous system, fat body, gonads, male accessory glands, flight muscles and salivary glands. The $S c g$-IRP transcript levels were most pronounced in

A

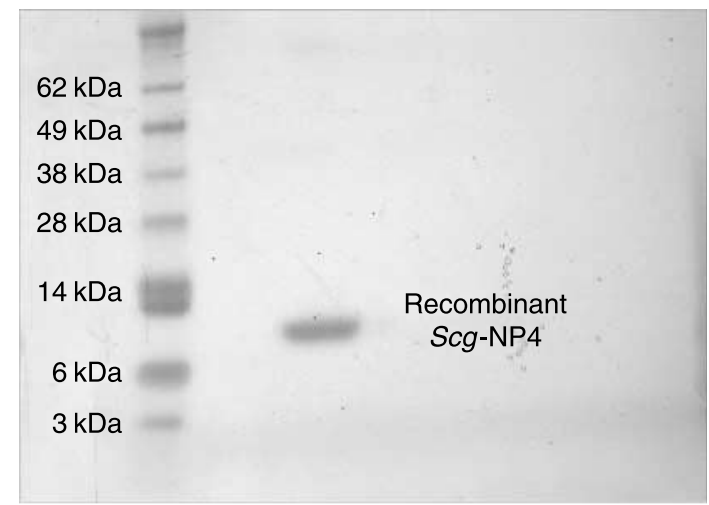

B
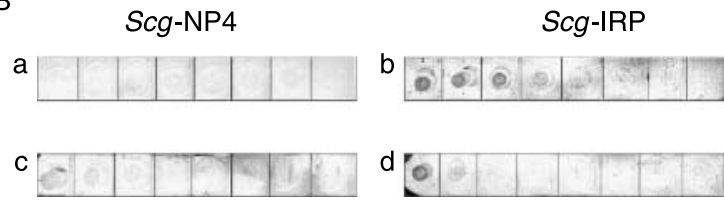

Figure 5 (A) SDS-PAGE analysis of an affinity purified sample containing biosynthetic Scg-NP4-V5-His. Culture medium (Drosophila SFM) containing the secreted Scg-NP4-V5-His protein was subjected to a one-step nickel chelate chromatography. The collected elution fractions contained a protein of $\sim 12 \mathrm{kDa}$, a molecular mass that corresponds to the calculated mass of ScgNP4-V5-His. Furthermore, no contaminating proteins were detected in the sample. Edman degradation confirmed the purified protein as Scg-NP4-V5-His. (B) Dot blot analysis of the wash and elution fractions of an in vitro binding assay between Scg-NP4V5-His (bound to a nickel column) and HPLC-purified Scg-IRP. All eight wash fractions were analyzed with an antibody raised against the V5-epitope, hence detecting (a) the presence of ScgNP4-V5-His, or with (b) an anti-Lom-IRP antiserum. In parallel, all eight elution fractions were incubated with either the antibody against (c) the V5 epitope or (d) anti-Lom-IRP antiserum. The results show that $S c g$-IRP was not only detected in the initial wash fractions, but was also eluted from the nickel column together with recombinant Scg-NP4. 
A

Scg-IRP
Lom-IRP
dilp1
dilp2
dilp3
dilp4
dilp5
dilp6
dilp7
AaegILP1
AaegILP2
AaegILP3
AaegILP4
AaegILP5
AaegILP6
AaegILP7
AaegILP8
AgamILP1_7
AgamILP2
AgamILP3-6
AgamILP4
AgamILP5
SaC-bombA1
Sac-bombA2
Sac-bombA3
Sac-bombB1
Sac-bombB2
bombyxin-A1
bombyxin-B1
bombyxin-C1
bombyxin-D1
bombyxin-E1
bombyxin-F1
bombyxin-G1
SI-ILP1
SI-ILP2
Agc-bombA
Agc-bombB
consensus

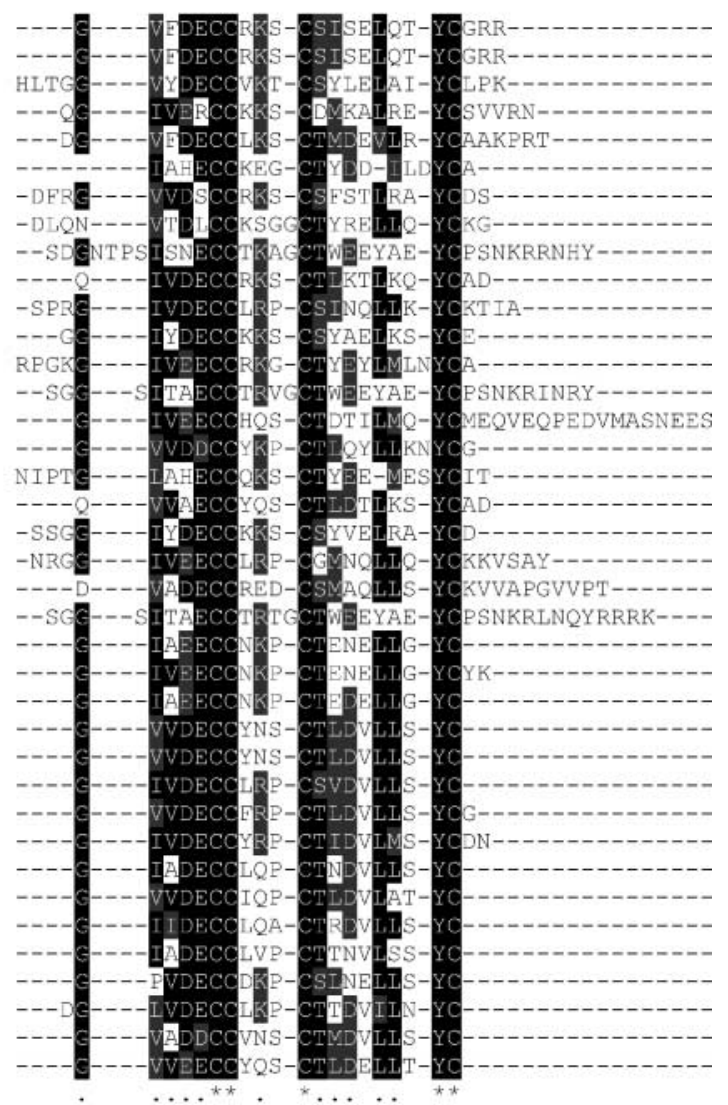

B

SCg-IRP

Lom-IRP

dilp1

dilp2

dilp 3

dilp 4
dilo 5

dilp6

dilp?

AaegILP1

AaegILP2

Aaeg ILPJ

AaegILP4

AaegILP5

AaegILPE

AaegIL?

AaegILPB

AgamILP1

AgamILP2

AgamILP3

AgamILP4

AgamILP5

Sac-bombA1

Sac-bombA2

Sac-bombA

Sac-bombB

Sac-bombB2

bombyxin-A]

bombyxin-B1

bombyxin-C1

bombyxin-D1

bombyxin-E1

bombyxin-E1

bombyxin-G1

SI-ILP1

SI-ILP2

Agc-bormb

Agc-bombB

consensus

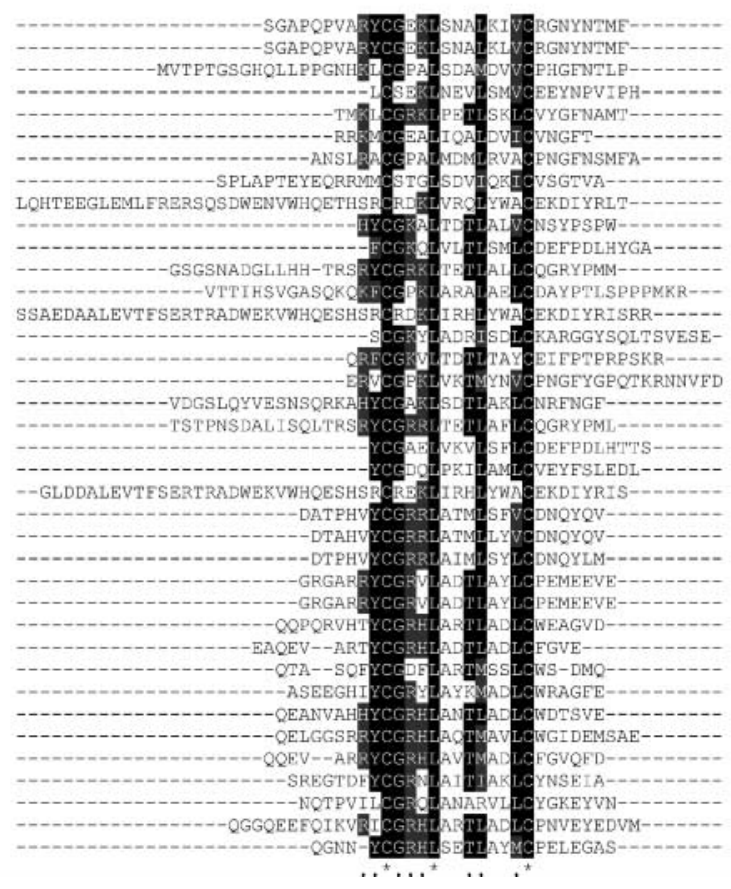


nervous tissue and in fat body. Figure 4 shows the relative quantities of $S c g$-IRP mRNA that were determined in brain and fat body of adult locusts as a function of gender and of age (4 and 10 days after adult emergence). Significant temporal fluctuation was noticed in the fat body of both adult males and females, as well as in the brain of adult gregarious females. In the fat body of gregarious males, the $S c g$-IRP transcripts reached a significantly higher level ( $c a$. threefold) at day 10, when compared with day 4 . This is contrary to the situation in the fat body of solitarious males, where relative $S c g$-IRP mRNA quantities were lower ( $c a$. twofold) at day 10 (Fig. 4B). As a result, significant differences in the $S c g$-IRP transcript levels were observed between solitarious and gregarious male fat bodies at day 10 . In gregarious female brains, the $S c g$-IRP mRNA shows a small but significant reduction in its abundance at day 10 , whereas in brains of solitarious females and both solitarious and gregarious males, this remains practically constant (Fig. 4A and C). In the fat body of gregarious females, a very pronounced increase ( $\geq 20$-fold) in the $S c g$-IRP transcript levels was noticed at day 10 , when compared with day 4 . In solitarious female fat bodies, a much smaller increase (ca. threefold) was observed (Fig. 4D).

\section{Binding to Scg-NP4}

Culture medium containing concentrated Scg-NP4-V5His was subjected to a one-step nickel ion chelate affinity chromatography. All elution fractions were tested for the presence of $S c g-\mathrm{NP} 4-\mathrm{V} 5$-His protein by means of SDSPAGE. Fractions containing the eluted protein were combined, desalted and concentrated. In the concentrated sample, one single protein band of $\sim 12 \mathrm{kDa}$ was observed by SDS-PAGE (Fig. 5A). This estimated molecular mass is in line with the calculated mass of Scg-NP4-V5-His (12 404.87 kDa). In addition, amino acid sequencing indeed identified the purified material as recombinant $S c g$-NP4-V5-His.

Figure 5B shows the results of the dot blot analysis in which wash and elution samples of the binding assay were tested for the presence of Scg-NP4-V5-His and/or
$S c g$-IRP. No (or only very weak) immunoreactivity was detected in any of the wash fractions which were incubated with the anti-V5 antibody, indicating that no detectable amount of $S c g$-NP4-V5-His was recovered from the resin during the washing steps (as expected, since the capacity of the column for the poly-His containing protein is quite high and possible unbound recombinant NPs had already been removed during rinsing steps prior to the incubation of the column with $S c g$-IRP). In contrast, wash fractions 1-5 were stained with decreasing intensity after treatment with the antibody raised against the A-chain of Lom-IRP. Wash fractions 6-8 did not show any immunopositive staining upon incubation with anti-Lom-IRP (A-chain) antibody, indicating that the unbound $S c g$-IRP was eliminated after the subsequent wash steps. Immunopositive staining was clearly observed in the first two elution fractions after incubation with anti-V5 monoclonal antibody, as well as after treatment with the anti-Lom-IRP antiserum. The same experiment was repeated twice with reproducible results. In addition, both antibodies did not show any cross-reactivity for each others targets and $S c g$-IRP was not retained on the column in control experiments in which no $S c g$-NP4-V5-His was added.

\section{Discussion}

In the present study, we describe the characterization of a novel member of the insulin superfamily in $S$. gregaria. The $S c g$-IRP was isolated from CC extracts by means of an HPLC-based purification strategy (Fig. 1). The resulting HPLC fractions were screened for the presence of an insulin-like substance by means of an antibody raised against the A-chain of Lom-IRP. Immunocytochemical data obtained with the same antibody (Fig. 2) indicated that the localization of the immunoreactive material in locust brain is in accordance with that of several other insect IRPs. Localization studies in various insects (Iwami et al. 1996a, Cao \& Brown 2001, Riehle et al. 2006, Van de Velde et al. 2007) demonstrated that many IRPs are produced in neurosecretory cells of the pars

Figure 6 Multiple sequence alignment of the (A) A-chain and (B) B-chain of several insect insulin-related peptides. The alignment was performed by ClustalW analysis (http://www.ebi.ac.uk/clustalw/), available from the European Bioinformatics Institute. All parameters were set at default values. Highly conserved residues are highlighted in black. Residues that are similar to the column's consensus are shaded. The consensus line includes the symbols: “*' representing a particular position at which an amino acid is completely conserved, '.' representing a position for which a consensus is defined, but at which not all amino acids are equal to the consensus. Abbreviations: ScgIRP, Schistocerca gregaria insulin-related peptide; Lom-IRP, Locusta migratoria insulin-related peptide (GenPept: P15131); dilp1-7, Drosophila melanogaster insulin-like peptide 1-7 (GenPept: Q9VT50, Q9VT51, Q9VT52, Q9VT53, Q7KUD5, Q9W4Z4, Q9W4Q9); AaegILP1-8, Aedes aegypti insulin-like peptide 1-8 (GenPept: ABI64116, ABI64118, ABI64117, ABI64119, ABI64124, ABI64122,

ABI64123, ABI64120); AgamlLP1_7, Anopheles gambiae insulin-like peptides 1 and 7 that are the product of a pair of duplicate genes, only differing in their C-peptides (GenPept: AAQ89692, AAQ89699); AgamILP3_6, A. gambiae insulin-like peptides 3 and 6 that are the product of a pair of duplicate genes, only differing in their C-peptides (GenPept: AAQ89694, AAQ89698); AgamlLP2,4,5, A. gambiae insulin-like peptides 2, 4 and 5 (GenPept: AAQ89693, AAQ89695, AAQ89697); Sac-bombA1-3/B1-2, Samia cynthia bombyxin-related peptide A1-3/B1-2 (GenPept: BAA03019, BAA03021, BAA03023, BAA03020, BAA03022); bombyxin A1-G1, Bombyx mori insulin-like peptides A1-G1 (GenPept: Q17192, P26733, P15410, P26736, P21808, P91896, O61271); S/-ILP1-2, Spodoptera littoralis insulin-like peptide 1-2 (29); Agc-bombA-B, Agrius convolvuli bombyxin-related peptide A-B (GenPept: O09209, O09210). 
intercerebralis, an important production site of neurohormones in insects. From there on, neurosecretory products are transported via the nervi corporis cardiaci (NCCI) to the storage part of the CC, where they reside until their release into the circulating hemolymph.

In combination with this immunological screening method, our research strategy has resulted in the purification of $S c g$-IRP, as well as in the determination of its amino acid sequence. The $S c g$-IRP possesses the typical structure of a metazoan insulin-like hormone (with the exception of vertebrate IGFs or IGFs and several Caenorhabditis elegans ILPs) that consists of A- and B-chains that are interconnected by Cys-bridges. Subsequently, the corresponding cDNA was cloned by means of a PCR- and RAcE-based strategy and sequenced (Fig. 3). The encoded hormone precursor exhibits a very similar organization as observed for most other members of the insulin superfamily. The pre-pro-Scg-IRP polypeptide indeed contains a signal peptide, which directs the hormone to the secretory pathway, as well as a pro-insulin portion with a B-, C- and A-chain. Upon removal of the signal peptide and the $\mathrm{C}$-chain, the Aand B-chains are covalently coupled by means of disulfide bridges and constitute the mature peptide. However, this desert locust IRP precursor still contains another peptide sequence that is situated between the signal sequence and the B-chain. This decapeptide has previously been termed 'IRP-copeptide'. Its existence was first demonstrated in the migratory locust, Locusta migratoria, where it may be involved in the regulation of carbohydrate metabolism (Clynen et al. 2003). The IRP co-peptide is identical in L. migratoria and S. gregaria. In contrast to the well-conserved sequences of $S c g$-IRP and IRP-copeptide, the C-chain is clearly less conserved between locust species (Fig. 3B). This observation is not unexpected, since, for all members of the insulin superfamily, the B- and A-chains are noticeably more conserved than the C-chain (Claeys et al. 2002). Multiple alignment of the newly identified $S c g$-IRP sequence with other known insect IRPs (Fig. 6) show that the cystein pattern in both the A- and B-chains is extremely well conserved. In addition, a tyrosine $(\mathrm{Y})$ and leucine $(\mathrm{L})$ residue in the A- and B-chains respectively, appear to occur in all known insect IRPs. Therefore, the observed results concerning the primary structure of the peptide and its cDNA indicate that pre-pro-Scg-IRP shares several general characteristics with other members of the insulin superfamily, while it also possesses some properties that may be more specific for locusts. In contrast to genomederived nucleotide sequence data obtained from lepidopteran, dipteran and hymenopteran species, only one single IRP has so far been identified in each of the orthopteran species, L. migratoria and S. gregaria. For both Lom-IRP and Scg-IRP, two transcript (cDNA) variants have now been identified, but these only differ in their $5^{\prime}$ untranslated region (Kromer-Metzger \&
Lagueux 1994). Since the genomes of these species have not (yet) been sequenced, it is still unclear whether other IRP genes remain to be discovered in these locusts.

Quantitative RT-PCR analysis revealed that the $S c g$-IRP transcripts occur in a wide variety of tissues, including nervous tissue and fat body, where expression levels were most pronounced. Our observation that IRP transcripts are not restricted to the brain is in line with several studies in other insects (Wu \& Brown 2006). Although bombyxins in B. moriare mainly expressed in neurosecretory cells of the brain, bombyxin A and B transcripts have also been detected in other ganglia, as well as in peripheral tissues (Iwami et al. 1996b). In D. melanogaster, the mRNAs for most dilps occur in both nervous and peripheral tissues (Brogiolo et al. 2001, Ikeya et al. 2002, Rulifson et al. 2002, Broughton et al. 2005). Moreover, in the migratory locust, L. migratoria, Lom-IRP transcripts were also found in a wide variety of tissues (Kromer-Metzger \& Lagueux 1994). The presence of IRP transcripts in various peripheral tissues may be an indication for a possible role of the encoded peptide(s) as a paracrine and/or endocrine signal substance, a situation that may resemble that of IGFs and many other growth factors. Our data also show the occurrence of a temporal fluctuation in relative $S c g$-IRP transcript quantities, especially in the fat body (Fig. 4). In adult, male and female, gregarious fat bodies, the $S c g$-IRP mRNA levels are significantly higher at day 10 after adult emergence, when compared with day 4 and with solitarious locusts. The fat body plays a key role in insect reproductive physiology. It is the major production site of vitellogenins (yolk protein precursors) that are released into the hemolymph and internalized in the growing oocytes. The entire process is believed to be under a strict hormonal control. Desert locust phases display remarkable differences in their reproductive physiology. Gregarious desert locusts show accelerated sexual maturation compared to their solitarious congeners (Uvarov 1966). In addition, the egg pods of gregarious females contain more eggs than those of solitarious females (90-160 eggs per gregarious egg pod versus a maximum of 80 eggs per solitarious egg pod; Uvarov 1966). On the other hand, solitarious females can produce more egg pods during their life time, since they tend to live longer (Claeys et al. 2005). In our gregarious locust lab cultures (the exact timing of the reproductive cycle may vary depending on culture conditions and food supply), the initial vitellogenic cycle in females started around day 6 after adult emergence, and resulted in well-developed ovaries around day 10. The first egg batches were deposited around day 14. In gregarious males, initial copulation behavior was also observed around day 10 . Therefore, the observed increase of $S c g$-IRP transcript levels in fat body occurred in parallel with the sexual maturation of gregarious animals, suggesting a possible link between the hormonally and phase-dependently controlled reproductive cycle and $S c g$-IRP expression. Various 
studies in other insects already indicated a possible role for IRP/ILP signaling in the control of insect reproduction. Fullbright et al. (1997) observed putative insulin receptors in ovarian cells of three different lepidopteran species, suggesting a function in ovarian development that may be similar to that of IGFs and relaxins in vertebrates. In Aedes aegypti, a mosquito insulin receptor (MIR) was also demonstrated in follicular cells, the primary source of ecdysteroids in adult females. In addition, MIR appeared to be expressed in function of the reproductive cycle (Riehle \& Brown 2002) and treatment with bovine insulin caused Ae. aegypti follicular cells to produce ecdysteroids (Riehle \& Brown 1999) that further stimulate vitellogenesis in this species. Female $D$. melanogaster require an intact insulin/IRP signaling pathway in the ovaries to regulate egg production in response to dietary changes (Drummond-Barbosa \& Spradling 2001). Moreover, mutations of the insulin receptor, a receptor tyrosine kinase, produced fruit fly phenotypes displaying impaired ovarian ecdysteroidogenesis (Tu et al. 2002), reduced folliculogenesis and juvenile hormone deficiency (Tatar 2004). Although the situation in locusts is less clear, various studies also suggested the existence of a (temporal) relationship between ovarian ecdysteroidogenesis and vitellogenesis (Girardie \& Girardie 1996, 1998, Tawfik et al. 1997, Girardie et al. 1998, Tawfik et al. 2002).

In addition to insulin (this study), locusts possess different NPs, which are structurally related to the $\mathrm{OEH}$ of mosquitoes and to vertebrate IGFBP (Badisco et al. 2007). In contrast to OEH, NP (i.c. Scg-NP1) was initially discovered as a factor that prevented oocyte growth and thus delayed the gonotropic cycle (Girardie et al. 1998). At present, four NPs (Scg-NP1-4) have been identified from S. gregaria (Janssen et al. 2001, Claeys et al. 2003), and in the fat body of adult gregarious locusts the transcripts coding for $S c g$-NP3 and for $S c g=\mathrm{NP} 4$ are strongly upregulated during sexual maturation, similarly as $S c g$-IRP. In the present study, we demonstrate the in vitro binding of recombinant $S c g$-NP4 with the purified, endogenous $S c g$-IRP (Fig. 5). This result represents the first experimental evidence that insect NPs possess the capacity to interact with insulin-related peptides, as IGFBPs do in vertebrates and perlustrin in the mollusk, $H$. laevigata (Weiss et al. 2001). If such interactions would also occur in vivo, NPs may exert regulatory effects situated upstream of IRP receptor signaling. These likely include effects that modulate molecular interactions, turnover, transport and tissue targeting of the corresponding insulin-like hormone(s) (Simonet et al. 2004). However, as exemplified by IGFBPs, this does not necessarily exclude the possible existence of additional modes of action (Mohan \& Baylink 2002). In the future, it will be of interest to further examine the in vivo role of $S c g$-IRP and to analyze whether $S c g$-NPs may exert an inhibiting or stimulating effect on its activities. Furthermore, more insight in the mechanisms controlling reproduction and phase transition could offer novel opportunities to improve prevention and control of locust swarms.

\section{Acknowledgements}

The authors especially thank Mark Brown (Athens, GA, USA) for his kind gift of antiserum and for his suggestions, R Jonckers for taking care of the insect cultures and J Puttemans for providing assistance with the figures. The authors gratefully acknowledge the $\mathrm{K} \mathrm{U}$ Leuven Research Foundation (GOA 2005/06), the Belgian Interuniversity Attraction Poles program (IUAP/PAI P6/14, Belgian Science Policy), the IWT and the FWO-Vlaanderen for financial support. EMBL accession numbers: AM889088 (Scg-IRP T1), AM889089 ( $S c g$-IRP T2). The authors declare that there is no conflict of interest that would prejudice the impartiality of this scientific work. The authors have nothing to declare.

\section{References}

Ayali A, Pener MP \& Girardie J 1996a Comparative study of neuropeptides from the corpora cardiaca of solitary and gregarious Locusta. Archives of Insect Biochemistry and Physiology 31 439-450.

Ayali A, Pener MP, Sowa SM \& Keeley LL 1996b Adipokinetic hormone content of the corpora cardiaca in gregarious and solitary migratory locusts. Physiological Entomology 21 167-172.

Badisco L, Claeys I, Van Loy T, Van Hiel M, Franssens V, Simonet G \& Vanden Broeck J 2007 Neuroparsins, a family of conserved arthropod neuropeptides. General and Comparative Endocrinology 153 64-71.

Bendtsen JD, Nielsen H, von Heijne G \& Brunak S 2004 Improved prediction of signal peptides: SignalP 3.0. Journal of Molecular Biology $340783-795$.

Brogiolo W, Stocker H, Ikeya T, Rintelen F, Fernandez R \& Hafen E 2001 An evolutionarily conserved function of the Drosophila insulin receptor and insulin-like peptides in growth control. Current Biology 11 213-221.

Broughton SJ, Piper MDW, Ikeya T, Bass TM, Jacobson J, Driege Y, Martinez P, Hafen E, Withers DJ, Leevers SJ et al. 2005 Longer lifespan, altered metabolism, and stress resistance in Drosophila from ablation of cells making insulin-like ligands. PNAS 102 3105-3110.

Brown MR, Graf R, Swiderek KM, Fendley D, Stracker TH, Champagne DE \& Lea AO 1998 Identification of a steroidogenic neurohormone in female mosquitoes. Journal of Biological Chemistry 273 3967-3971.

Cao C \& Brown MR 2001 Localization of an insulin-like peptide in brains of two flies. Cell and Tissue Research 304 317-321.

Claeys I, Simonet G, Poels J, Van Loy T, Vercammen L, De Loof A \& Vanden Broeck J 2002 Insulin-related peptides and their conserved signal transduction pathway. Peptides 23 807-816.

Claeys I, Simonet G, Van Loy T, De Loof A \& Vanden Broeck J 2003 cDNA cloning and transcript distribution of two novel members of the neuroparsin family in the desert locust, Schistocerca gregaria. Insect Molecular Biology 12 473-481.

Claeys I, Simonet G, Breugelmans B, Van Soest S, Franssens V, Sas F, De Loof A \& Vanden BroeckJ 2005 Quantitative real-time RT-PCR analysis in desert locusts reveals phase dependent differences in neuroparsin transcript levels. Insect Molecular Biology 14 415-422. 
Clynen E, Huybrechts J, Baggerman G, Van Doorn J, Van der Horst D, De Loof A \& Schoofs L 2003 Identification of a glycogenolysisinhibiting peptide from the corpora cardiaca of locusts. Endocrinology 144 3441-3448.

Collip JB 1923 The demonstration of an insulin-like substance in the tissues of the clam (Mya arenaria). Journal of Biological Chemistry 55 R39.

Drummond-Barbosa D \& Spradling AC 2001 Stem cells and their progeny respond to nutritional changes during Drosophila oogenesis. Developmental Biology 231 265-278.

Fullbright G, Lacy ER \& Bullesbach EE 1997 The prothoracicotropic hormone bombyxin has specific receptors on insect ovarian cells. European Journal of Biochemistry 245 774-780.

Girardie J \& Girardie A 1996 Lom OMP, a putative ecdysiotropic factor for the ovary in Locusta migratoria. Journal of Insect Physiology 42 215-221.

Girardie J \& Girardie A 1998 Endocrine regulation of oogenesis in insects. Trends in Comparative Endocrinology and Neurobiology 839 118-122.

Girardie J, Girardie A, Huet JC \& Pernollet JC 1989 Amino acid sequence of locust neuroparsins. FEBS Letters 245 4-8.

Girardie J, Huet JC, Atay-Kadiri Z, Ettaouil S, Delbecque JP, Fournier B, Pernollet JC \& Girardie A 1998 Isolation, sequence determination, physical and physiological characterization of the neuroparsins and ovary maturing parsins of Schistocerca gregaria. Insect Biochemistry and Molecular Biology 28 641-650.

Hetru C, Li KW, Bulet P, Lagueux M \& Hoffmann JA 1991 Isolation and structural characterization of an insulin-related molecule, a predominant neuropeptide from Locusta migratoria. European Journal of Biochemistry 201 495-499.

Hoste B, Luyten L, Claeys I, Clynen E, Rahman MM, De Loof A \& Breuer M 2002 An improved breeding method for solitarious locusts. Entomologia Experimentalis et Applicata 104 281-288.

Ikeya T, Galic M, Belawat P, Nairz K \& Hafen E 2002 Nutrientdependent expression of insulin-like peptides from neuroendocrine cells in the CNS contributes to growth regulation in Drosophila. Current Biology 12 1293-1300.

Iwami M, Furuya I \& Kataoka H 1996a Bombyxin-related peptides, cDNA structure and expression in the brain of the hornworm Agrius convoluvuli. Insect Biochemistry and Molecular Biology 26 25-32.

Iwami M, Tanaka A, Hano N \& Sakurai S 1996b Bombyxin gene expression in tissues other than brain detected by reverse transcription polymerase chain reaction (RT-PCR) and in situ hybridization. Experientia 52 882-887.

Janssen T, Claeys I, Simonet G, De Loof A, Girardie J \& Vanden Broeck J 2001 CDNA cloning and transcript distribution of two different neuroparsin precursors in the desert locust, Schistocerca gregaria. Insect Molecular Biology 10 183-189.

Krieger MJB, Jahan N, Riehle MA, Cao C \& Brown MR 2004 Molecular characterization of insulin-like peptide genes and their expression in the African malaria mosquito, Anopheles gambiae. Insect Molecular Biology 13 305-315.

Kromer-Metzger E \& Lagueux M 1994 Expression of the gene encoding an insulin-related peptide in Locusta (Insecta, Orthoptera). Evidence for alternative promoter usage. European Journal of Biochemistry 221 427-434.

Laemmli UK 1970 Cleavage of structural proteins during the assembly of the head of bacteriophage T4. Nature 227 680-685.

Lagueux M, Lwoff L, Meister M, Goltzene F \& Hoffmann JA 1990 cDNAs from neurosecretory cells of brains of Locusta migratoria (Insecta, Orthoptera) encoding a novel member of the superfamily of insulins. European Journal of Biochemistry 187 249-254.

Mohan S \& Baylink DJ 2002 IGF-binding proteins are multifunctional and act via IGF-dependent and -independent mechanisms. Journal of Endocrinology 175 19-31.

Nagasawa H, Kataoka H, Isogai A, Tamura S, Suzuki A, Mizoguchi A, Fujiwara Y, Suzuki A, Takahashi SY \& Ishizaki H 1986 Amino acid sequence of a prothoracicotropic hormone of the silkworm Bombyx mori. PNAS 83 5840-5843.
Pener MP \& Yerushalmi Y 1998 The physiology of locust phase polymorphism: an update. Journal of Insect Physiology 44 365-377.

Riehle MA \& Brown MR 1999 Insulin stimulates ecdysteroid production through a conserved signaling cascade in the mosquito Aedes aegypti. Insect Biochemistry and Molecular Biology 29 855-860.

Riehle MA \& Brown MR 2002 Insulin receptor expression during development and a reproductive cycle in the ovary of the mosquito Aedes aegypti. Cell and Tissue Research 308 409-420.

Riehle MA, Fan YL, Cao C \& Brown MR 2006 Molecular characterization of insulin-like peptides in the yellow fever mosquito, Aedes aegypti: expression, cellular localization, and phylogeny. Peptides $\mathbf{2 7}$ 2547-2560.

Rulifson EJ, Kim SK \& Nusse R 2002 Ablation of insulin-producing neurons in flies: growth and diabetic phenotypes. Science $\mathbf{2 9 6}$ 1118-1120.

Simonet G, Poels J, Claeys I, Van Loy T, Franssens V, De Loof A \& Vanden Broeck J 2004 Neuroendocrinological and molecular aspects of insect reproduction. Journal of Neuroendocrinology 16 649-659.

Tatar M 2004 The neuroendocrine regulation of Drosophila aging. Experimental Gerontology 39 1745-1750.

Tawfik AI, Vedrova A, Li WW, Sehnal F \& ObengOfori D 1997 Haemolymph ecdysteroids and the prothoracic glands in the solitary and gregarious adults of Schistocerca gregaria. Journal of Insect Physiology 43 485-493.

Tawfik AI, Tanaka S, De Loof A, Schoofs L, Baggerman G, Waelkens E, Derua R, Milner Y, Yerushalmi Y \& Pener MP 1999 Identification of the gregarization-associated dark-pigmentotropin in locusts through an albino mutant. PNAS 96 7083-7087.

Tawfik AI, Tanaka Y \& Tanaka S 2002 Possible involvement of ecdysteroids in embryonic diapause of Locusta migratoria. Journal of Insect Physiology 48 743-749.

Tu MP, Yin CM \& Tatar M 2002 Impaired ovarian ecdysone synthesis of Drosophila melanogasterinsulin receptor mutants. Aging Cell 1 158-160.

Uvarov B 1966 Phase polymorfism. In Grasshoppers and Locusts, vol 1, pp 332-387. Cambridge, UK: Cambridge University Press.

Vanden Broeck J 2001 Neuropeptides and their precursors in the fruitfly, Drosophila melanogaster. Peptides 22 241-254.

Vanden Broeck J, Chiou SJ, Schoofs L, Hamdaoui A, Vandenbussche F, Simonet G, Wataleb S \& De Loof A 1998 Cloning of two cDNAs encoding three small serine protease inhibiting peptides from the desert locust Schistocerca gregaria and analysis of tissue-dependent and stage-dependent expression. European Journal of Biochemistry 254 90-95.

Vandesande F \& Dierickx K 1976 Immunocytochemical demonstration of separate vasotocinergic and mesotocinergic neurons in amphibian hypothalamic magnocellular neurosecretory system. Cell and Tissue Research 175 289-296.

Van de Velde S, Badisco L, Claeys I, Verleyen P, Chen X, Vanden Bosch L, Vanden BroeckJ \& Smagghe G 2007 Insulin-like peptides in Spodoptera littoralis (Lepidoptera): detection, localization and identification. General and Comparative Endocrinology 153 72-79.

Weiss IM, Gohring W, Fritz M \& Mann K 2001 Perlustrin, a Haliotis laevigata (abalone) nacre protein, is homologous to the insulin-like growth factor binding protein N-terminal module of vertebrates. Biochemical and Biophysical Research Communications 285 244-249.

Wheeler DE, Buck N \& Evans JD 2006 Expression of insulin pathway genes during the period of caste determination in the honey bee, Apis mellifera. Insect Molecular Biology 15 597-602.

Wu Q \& Brown MR 2006 Signaling and function of insulin-like peptides in insects. Annual Review of Entomology 51 1-24.

Received in final form 21 December 2007

Accepted 10 January 2008

Made available online as an Accepted Preprint

10 January 2008 